\title{
Contrast Between Orange- and Black-Colored Sclerotial Isolates of Botrytis cinerea: Melanogenesis and Ecological Fitness
}

Yingjun Zhou, State Key Laboratory of Agricultural Microbiology, Huazhong Agricultural University, Wuhan 430070, China, and Institute of Bast Fiber Crops, Chinese Academy of Agricultural Sciences, Changsha 410205, China; Na Li, Jingyi Yang, Long Yang, and Mingde Wu, State Key Laboratory of Agricultural Microbiology and Key Laboratory of Plant Pathology of Hubei Province, Huazhong Agricultural University; Weidong Chen, United States Department of Agriculture-Agricultural Research Service, Washington State University, Pullman; and Guoqing Li, and Jing Zhang, ${ }^{\dagger}$ State Key Laboratory of Agricultural Microbiology, Huazhong Agricultural University

\begin{abstract}
Botrytis cinerea usually produces grayish mycelia and conidia as well as black-colored sclerotia (BS) due to accumulation of melanin. An isolate $(\mathrm{XN}-1)$ of $B$. cinerea producing orange-colored sclerotia (OS) on agar media was obtained from an orange-colored apothecium of an uncultured soil fungus. Whether or not the OS B. cinerea occurs on plants and how they differ from the BS isolates in melanogensis and ecological fitness remained unknown. This study, for the first time, confirmed the presence of the OS B. cinerea in strawberry and tomato plants that were surveyed in Hubei Province of China. Only five OS isolates were obtained from a

total of 2,031 isolates surveyed from the two crops. The OS isolate $\mathrm{XN}-1$ was compared and contrasted with the BS isolate B05.10 in sclerotial melanogenesis and ecological fitness. Sclerotial melanogenesis was evident in B05.10 but was deficient in XN-1. The OS were more susceptible to the two mycoparasites Trichoderma koningiopsis and Clonostachys rosea than the BS. The percentage of viable sclerotia after the mycoparasitism study was significantly $(P<0.01)$ lower in OS $(21 \%)$ than in BS $(48 \%)$. This study also reaffirmed the importance of melanization for survival of $B$. cinerea sclerotia.
\end{abstract}

Botrytis cinerea Pers. (teleomorph Botryotinia fuckeliana (de Bary) Whetzel) is the causal agent of gray mold, a common disease on many crops in cool and temperate areas of the world. It can infect more than 1,400 plant species, including many economically important fruit, vegetable, ornamental, and field crops (Elad et al. 2016). It is estimated that the global expenditure for control of pre- or postharvest diseases caused by Botrytis spp. (mainly Botrytis cinerea) exceeds $\$ 1.1$ billion per year (Dean et al. 2012).

The complete life cycle of $B$. cinerea consists of four morphologically and functionally different structures: ascospores, conidia (microconidia or macroconidia), mycelia, and sclerotia. Although the sexual cycle (ascospores) rarely occurs in nature (Polach and Abawi 1975), the asexual cycle usually predominates and appears to be responsible for the polycyclic epidemics of $B$. cinerea (Williamson et al. 2007). As a result, graycolored conidia and mycelia of $B$. cinere $a$ are frequently produced on infected plant tissues.

Conidia, the infective organ of $B$. cinerea, are borne from germinating sclerotia or from hyphae that infected plant tissues or debris, and they usually spread by air currents. In addition, conidia germinate to initiate infection under the stimulation of exogenous nutrients (e.g., senescent flower petals, pollen grains, and insect honeydew). Conidia also possess considerable survival potential from minutes to 1 year, depending on isolates and the conidial age, as well as on environmental conditions such as temperature, relative humidity, and sunlight (UV) irradiation (Salinas et al. 1989; Walter et al. 1999).

Mycelia, which mostly are regarded as the vegetative structures for substrate colonization and nutrient absorption, also possess survival potential. Studies done in Canada, Israel, and Spain showed that B. cinerea survived harsh summer or winter seasons mostly as mycelia in plant debris (Raposo et al. 1996; Yunis and Elad 1989). Sclerotia, which are encrusted and compacted masses of mycelia, are overwintering structures for surviving in adverse environmental conditions

${ }^{\dagger}$ Corresponding authors: J. Zhang, E-mail: zhangjing1007@mail.hzau.edu.cn

*The $\boldsymbol{e}$-Xtra logo stands for "electronic extra" and indicates that two supplementary figures are published online.

Accepted for publication 16 September 2017.

() 2018 The American Phytopathological Society such as desiccation, low or high temperatures, UV irradiation, and microbial attack. Hsiang and Chastagner (1992) reported that sclerotia of Botrytis spp. produced in vitro could survive in the soil for at least 18 months, and possibly serve as the primary infection source when conditions become favorable. However, the importance of sclerotia as the primary infection source in nature remains controversial, because they are not frequently observed in all infected plant tissues (Raposo et al. 1996; Yunis and Elad 1989).

Sclerotia of $B$. cinerea are generally black colored, and conidia and hyphae of this fungus are usually gray colored. The cell wall of these structures was found to have deposition of 1,8-dihydroxynaphthalene (DHN) melanin (Schumacher 2016; Zeun and Buchenauer 1985). It is well recognized that melanin is a multifunctional antistress pigment conferring fungal resistance (or tolerance) against desiccation, UV irradiation, enzymatic lysis, toxic chemicals, and extreme temperatures. Moreover, in some plant-pathogenic fungi such as Colletotrichum lagenarium and Magnaporthe oryzae, DHN melanin functions as a virulence (or pathogenicity) determinant, assisting infection of plant tissues through the action of melanized appressoria (Howard and Valent 1996; Kubo et al. 1982). In B. cinerea, DHN melanin on conidia, hyphae, and sclerotia mostly functions as a stress protectant rather than a pathogenicity or virulence factor (Schumacher 2016).

In spring (April) 2012, a B. cinerea isolate (XN-1) was obtained from an apothecium of an uncultured soil fungus collected from a strawberry farm in Xianning County of Hubei Province, China. It formed unusually orange-colored sclerotia (OS) on potato dextrose agar. However, whether the OS B. cinerea occur on plants and how they differ from the black-colored sclerotia (BS) in terms of biological characteristics (growth, development, and survival) remained unknown. This study was conducted with the following two objectives: (i) to survey the prevalence of OS B. cinerea in tomato and strawberry plants in the Hubei Province of China and (ii) to compare and contrast the biological and ecological characteristics of the selected OS and BS isolates.

\section{Materials and Methods}

Field surveys. The OS isolate $\mathrm{XN}-1$ was obtained from an apothecium collected from a strawberry production farm using the procedure shown in Figure 1. For isolation of the OS B. cinerea in plants, 104 tomato and 148 strawberry fields in 15 counties of Hubei Province in central China were surveyed for gray mold disease between December to May 2013 and 2014 (Fig. 2). Diseased leaves, flowers, and fruit with gray mold symptoms were detached, and 3 to 10 samples were 
collected from each field. These samples were taken to the laboratory for single-conidium isolation using the procedures described by Zhang and colleagues (2010), one isolate from each plant sample. The resulting isolates were incubated at $20^{\circ} \mathrm{C}$ for 30 days and identified based on colony morphology (mycelia, conidia, and sclerotia) (Zhou et al. 2014).

Ten selected isolates of $B$. cinerea were used in this study (Table 1). Six isolates (S443, S417, S494, T415, T417, and XN-1) produced OS, whereas the remaining four isolates (BC-27, B05.10, HS-5, and WXto2-2) produced BS. Identity of the six OS isolates as $B$. cinere $a$ was confirmed by $B$. cinerea-specific polymerase chain reaction (PCR) detection (Fan et al. 2015). Meanwhile, the internal transcribed spacer (ITS) ribosomal DNA (rDNA) sequences in five selected isolates (XN-1, S417, T417, HS-5, and BC-27) were PCR amplified using the primer set ITS1/ITS4 (Zhou et al. 2014). The PCR products were sequenced. The resulting DNA sequences were submitted to the GenBank public database.

Mycelial growth and sclerotial development assays. Ten selected isolates of $B$. cinerea (Table 1 ) were cultured on potato dextrose agar (PDA) in 9-cm-diameter Petri dishes. The cultures were incubated at $20^{\circ} \mathrm{C}$ in the dark. Each isolate was replicated five times. Colony diameter was measured after 2 to 3 days of incubation. Difference in colony diameter between two measurements was used to

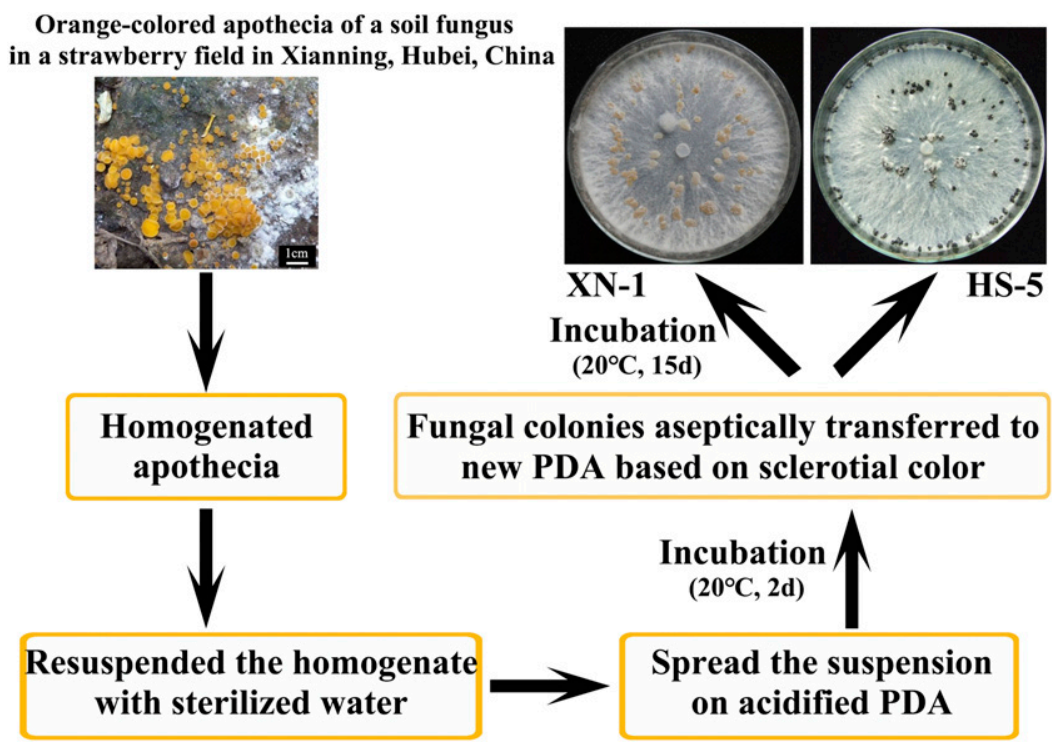

Fig. 1. Collection and culturing of orange-colored apothecia produced by an uncultured soil fungus in a strawberry field at the time of survey of Botrytis cinerea in Xianning County, Hubei Province, China. Two isolates of $B$. cinerea (XN-1 and HS-5) used in this study were obtained from the sampled apothecia. PDA = potato dextrose agar.
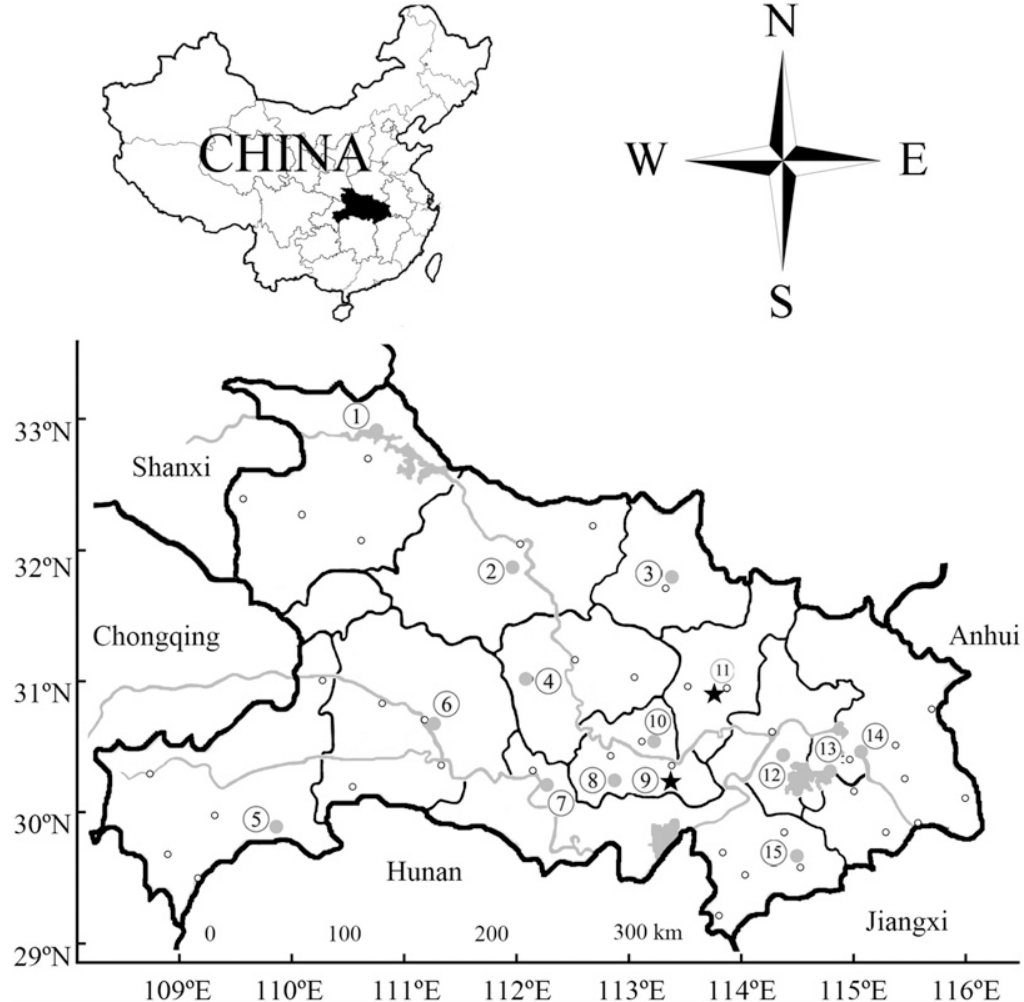

\begin{tabular}{|c|c|c|}
\hline County & OS & BS \\
\hline Shiyan & 0 & 36 \\
\hline Xiangyang & 0 & 167 \\
\hline Suizhou & 0 & 56 \\
\hline Jinmen & 0 & 117 \\
\hline Enshi & 0 & 4 \\
\hline Yichang & 0 & 147 \\
\hline Jinzhou & 0 & 74 \\
\hline Qianjiang & 0 & 78 \\
\hline Xiantao & 3 & 75 \\
\hline Tianmen & 0 & 3 \\
\hline Xiaogan & 2 & 165 \\
\hline Wuhan & 0 & 95 \\
\hline Ezhou & 0 & 23 \\
\hline Huanggang & 0 & 64 \\
\hline Xianning & 0 & 922 \\
\hline Tota & 5 & \\
\hline
\end{tabular}

Fig. 2. Field survey of the orange-colored sclerotial (OS) isolates of Botrytis cinerea on strawberry and tomato in Hubei Province, China. Five-pointed stars in the map indicate the place where the OS isolates were obtained. The number of isolates of each type from each county is presented in the table on the right. 
estimate mycelial growth rate (Zhou et al. 2014). The cultures were further incubated for 4 to 28 days for observation of sclerotial development.

Conidial germination assay. Isolates $\mathrm{XN}-1$ (OS) and $\mathrm{B} 05.10$ (BS) were incubated at $20^{\circ} \mathrm{C}$ on malt yeast agar medium $(20 \mathrm{~g}$ of malt extract, $5 \mathrm{~g}$ of yeast extract, $12.5 \mathrm{~g}$ of agar powder, and $1,000 \mathrm{ml}$ of water) in Petri dishes under light for 15 days. Sterile distilled water (SDW) was added to the dishes (10 ml per dish) and the colonies were gently rubbed with a sterilized spatula to dislodge the conidia. The resulting mixtures were filtered through four layers of sterilized cheesecloth to obtain conidial suspensions of $1 \times 10^{5}$ conidia $/ \mathrm{ml}$, and $200 \mu \mathrm{l}$ of this suspension was pipetted onto water agar (WA) in each Petri dish, evenly plated, then incubated at $20^{\circ} \mathrm{C}$ with three Petri dishes (replicates) for each isolate. After incubation for $9 \mathrm{~h}$, percent conidial germination was examined by randomly counting at least 100 conidia in each dish.

Microscopy. A mature sclerotium, approximately $5 \mathrm{~mm}$ in diameter, was randomly chosen from 30-day-old PDA cultures of XN-1 or B05.10 and carefully embedded in paraffin wax. The specimens were cut to $12-\mu \mathrm{m}$-thick slices, which were then mounted on glass slides, dewaxed, stained with toluidine blue, and, finally, observed under a compound light microscope.

Two sclerotia, one from XN-1 and the other from B05.10, were carefully detached from 20 -day-old PDA cultures $\left(20^{\circ} \mathrm{C}\right)$ for scanning electron microscopy (SEM) and transmission electron microscopy (TEM). For SEM, the epidermal layer (approximately $0.5 \mathrm{~mm}$ thick) was immediately peeled off from the sclerotia using a razor blade immersed in the glutaraldehyde fixative, followed by dehydration with ethanol using a 13200-EAB model Critical Point Dryer (SPI Supplies, West Chester, PA), and gold coated in a sputter coater (model JFC1600; NTC, Tokyo). Finally, the specimens were observed under a scanning electron microscope (model JSM-6390/LV; NTC).

Four pieces of the sclerotial epidermal layer (approximately 3 by 2 by $1 \mathrm{~mm}$ [length by width by thickness]) from the sclerotia of $\mathrm{XN}-1$ or B05.10 were also prepared for TEM following the standard procedure. The specimens were observed using a transmission electronic microscope (model Tecnai G ${ }^{2} 20$ S-TWIN; FEI Company, Hillsboro, OR) at $75 \mathrm{kV}$.

Sclerotial survival assay. Sclerotia of isolates $\mathrm{XN}-1$ (OS) and B05.10 (BS) were harvested from 20-day-old PDA cultures $\left(20^{\circ} \mathrm{C}\right)$. After air drying at room temperature, the sclerotia of each isolate were buried in yellow-brown clay soil in 216 Petri dishes $(9 \mathrm{~cm}$ in diameter), with 15 sclerotia per Petri dish. The dishes were divided into three lots (72 dishes each) for low, moderate, and high water contents, with 6,19 , and
$45 \%$ water (wt/wt), respectively. The Petri dishes for each water-content treatment were further divided into three sublots, 24 dishes per sublot, which were placed in three incubators at 10,20 , and $30^{\circ} \mathrm{C}$, respectively. Two dishes in each treatment (isolate-temperature-water content) were randomly sampled right after the sclerotial burial and at 30-day intervals thereafter for 360 days. The sclerotia were retrieved, surface disinfected using $0.1 \% \mathrm{HgCl}_{2}$ (wt/vol), rinsed in SDW, and placed on PDA to determine their viability based on producing new colonies of $B$. cinerea. The percentage of viable sclerotia (VS) at the given days postincubation was calculated using the formula VS $(\%)=$ VS/TS $\times 100$, where VS and TS represent numbers of the viable sclerotia and total number of sclerotia, respectively, of each isolate at given days postincubation. Meanwhile, area under sclerotial survival curve (AUSSC) was calculated for each treatment (temperature-soil water content) based on percentages of VS and related time periods using the formula AUSSC $=\left[\left(X_{i}+X_{i+1}\right) / 2\right] \times\left(T_{i+1}-T_{i}\right)$, where $X_{i}$ and $X_{i+1}$ are the percentages of VS at sampling serial numbers $i$ and $i+1$, respectively, and $T_{i}$ and $T_{i+l}$ are the days postincubation at the sampling time points $i$ and $i+1$, respectively.

Mycoparasitism assay. Sclerotia of isolates $\mathrm{XN}-1$ and B05.10 were harvested from 20 -day-old PDA cultures $\left(20^{\circ} \mathrm{C}\right)$, air dried at room temperature, and exposed to two mycoparasitic fungi of $B$. cinerea, Clonostachys rosea CanS-48, and Trichoderma koningiopsis T-51, which were included to test difference between OS and BS in susceptibility to mycoparasitic infection. Isolate CanS-48 was isolated from a healthy stem of oilseed rape (Brassica napus) (Zhang et al. 2014). Isolate T-51 of T. koningiopsis was isolated from a soil sample (You et al. 2016). Conidia of CanS-48 and T-51 were harvested from 15-day-old PDA cultures $\left(20^{\circ} \mathrm{C}\right)$ by washing with SDW and the resulting conidial suspensions were adjusted to $1 \times 10^{7}$ conidia/ml. The sclerotia of each isolate were soaked for $30 \mathrm{~min}$ in $10 \mathrm{ml}$ of conidial suspension of each mycoparasite or in $10 \mathrm{ml}$ of water (control). Then, the sclerotia were blotted dry on sterilized paper towels and transferred to sterilized fine sand in Petri dishes, with 15 sclerotia/dish and three dishes for each treatment. SDW was added to the dishes to moisturize the sand. The dishes were placed in an incubator at $28^{\circ} \mathrm{C}$. After incubation for 15 days, the sclerotia were collected, surface disinfected with $70 \%$ ethanol, soaked in water twice ( 1 min each time), and placed on PDA plates. The cultures were incubated at $20^{\circ} \mathrm{C}$ for 4 days. The colonies formed from the sclerotia were individually transferred to new PDA plates, which were incubated again at $20^{\circ} \mathrm{C}$ for another 10 days. The resulting cultures were identified based on the morphological characteristics of Botrytis cinerea, $C$. rosea, and T. koningiopsis. The experiment was repeated three times.

Table 1. Origin of the 10 selected isolates of Botrytis cinerea, their mycelial growth rate (millimeters per day) on potato dextrose agar after 2 to 3 days of incubation at $20^{\circ} \mathrm{C}$, and percentage of germinated conidia on water agar after $9 \mathrm{~h}$ of incubation at $20^{\circ} \mathrm{C}^{\mathrm{y}}$

\begin{tabular}{|c|c|c|c|c|c|}
\hline Isolate & $\begin{array}{l}\text { Sclerotial } \\
\text { color }\end{array}$ & Origin (location, year) & Host plant & $\begin{array}{l}\text { Mycelial growth rate }(\mathrm{mm} / \mathrm{day}) \\
\qquad(n=3)\end{array}$ & $\begin{array}{l}\text { Percent germinated conidia } \\
\qquad(n=3)\end{array}$ \\
\hline S443 & Orange & $\begin{array}{l}\text { Xiantao County, Hubei, China, } \\
2013\end{array}$ & Fragaria $\times$ ananassa & $17.1 \mathrm{a}$ & $99.7 \mathrm{a}$ \\
\hline S417 & Orange & $\begin{array}{l}\text { Xiantao County, Hubei, China, } \\
2013\end{array}$ & Fragaria $\times$ ananassa & $15.0 \mathrm{a}$ & $98.3 \mathrm{a}$ \\
\hline S494 & Orange & $\begin{array}{l}\text { Xiantao County, Hubei, China, } \\
2013\end{array}$ & Fragaria $\times$ ananassa & $16.3 \mathrm{a}$ & $99.3 \mathrm{a}$ \\
\hline T415 & Orange & $\begin{array}{l}\text { Xiaochang County, Hubei, China, } \\
2013\end{array}$ & $\begin{array}{l}\text { Lycopersicon } \\
\text { esculentum }\end{array}$ & $17.3 \mathrm{a}$ & $98.3 \mathrm{a}$ \\
\hline T417 & Orange & $\begin{array}{l}\text { Xiaochang County, Hubei, China, } \\
2013\end{array}$ & L. esculentum & $14.8 \mathrm{a}$ & $99.0 \mathrm{a}$ \\
\hline $\mathrm{XN}-1$ & Orange & $\begin{array}{l}\text { Xianning County, Hubei, China, } \\
2012\end{array}$ & Unknown ${ }^{\mathrm{z}}$ & $17.6 \mathrm{a}$ & $99.0 \mathrm{a}$ \\
\hline B05.10 & Black & Germany & Vitis vinifera & $16.7 \mathrm{a}$ & $98.0 \mathrm{a}$ \\
\hline BC-27 & Black & $\begin{array}{l}\text { Badong County, Hubei, China, } \\
2007\end{array}$ & Vicia faba & $16.1 \mathrm{a}$ & $99.7 \mathrm{a}$ \\
\hline HS-5 & Black & $\begin{array}{l}\text { Xianning County, Hubei, China, } \\
2012\end{array}$ & Unknown $^{\mathrm{z}}$ & $16.3 \mathrm{a}$ & $99.0 \mathrm{a}$ \\
\hline WXto2-2 & Black & $\begin{array}{l}\text { Wuxue County, Hubei, China, } \\
2013\end{array}$ & L. esculentum & $15.3 \mathrm{a}$ & $90.3 \mathrm{~b}$ \\
\hline
\end{tabular}

\footnotetext{
${ }^{y}$ Means followed by the same letters within a column are not significantly different according to a least significant difference test at $P>0.05$.

${ }^{\mathrm{z}}$ From an apothecium of an unknown fungus.
} 
Abiotic stress assay on sclerotia. Thirty sclerotia of $\mathrm{XN}-1$ or B05.10 from 20-day-old PDA cultures $\left(20^{\circ} \mathrm{C}\right)$ were soaked in D-sorbitol at $1 \mathrm{~mol} / \mathrm{liter}, \mathrm{NaCl}$ at $1 \mathrm{~mol} / \mathrm{liter}, 30 \%$ (vol/vol) $\mathrm{H}_{2} \mathrm{O}_{2}$, and $10 \%(\mathrm{wt} / \mathrm{vol}$ ) sodium dodecyl sulfate (SDS) for different time durations. Six time durations (in days or hours) were investigated for D-sorbitol and $\mathrm{NaCl}\left(0,6,12,18,24\right.$, and 30 days), $\mathrm{H}_{2} \mathrm{O}_{2}(0,0.5,1.0,1.5$, 2.0, and $2.5 \mathrm{~h})$, and $\operatorname{SDS}(0,1,2,3,4$, and $5 \mathrm{~h})$. At each time point, the sclerotia were taken out of each solution and surface sterilized in $70 \%$ ethanol for $3 \mathrm{~min}$. After rinsing in SDW twice (1 min each time), the sclerotia were placed on PDA and the cultures were incubated at $20^{\circ} \mathrm{C}$ for 5 days. The number of the fungal colonies growing from the sclerotia in each dish was recorded to calculate the sclerotial survival rate.

Data analysis. The procedure of analysis of variance in the SAS software (v. 8.0, 1999; SAS Institute, Cary, NC) was used to determine significant differences between isolates of $B$. cinerea in radial growth rate and number of sclerotia in each dish on each agar medium. Treatment means on each of the above-mentioned parameters for the different isolates were separated using the least significant difference (LSD) test at $\alpha=0.05$. The procedure Univariate in SAS was used to analyze the data on percentages of viable OS and BS sclerotia (survival rates) in the treatments of control, T. koniningiopsis, and C. rosea. Means in each parameter for the BS and OS isolates as two groups were compared using Student's $t$ test at $\alpha=0.05$ or 0.01 . In all of the SAS analyses, the percentage data on rates of germinated conidia and VS were arcsin-transformed to angular values. After analysis, the average angular values were individually back-transformed to numerical values.

\section{Results}

Natural occurrence of OS isolates of $B$. cinerea. The first OS isolate $\mathrm{XN}-1$ of $B$. cinerea and BS isolate HS-5 were isolated from apothecia collected from a strawberry field (Fig. 1; Table 1). Results of the field surveys showed that 5 of a total of 2,031 isolates (accounting for $0.25 \%$ ) collected from strawberry and tomato grown in 15 counties (Fig. 2; Table 1) produced OS. The remaining 2,026 isolates (accounting for $99.8 \%$ ) produced BS. All 922 isolates collected from Xianning County, Hubei Province, China, where XN-1 was isolated, belonged to the BS type.
Six OS isolates (XN-1, S443, S417, S494, T415, and T417) and three BS isolates (B05.10, BC-27, and HS-5) had the typical morphological characteristics of $B$. cinerea (Fig. 3; Table 2). They produced a 354-bp DNA fragment in PCR with the $B$. cinerea-specific primers Bc-f and Bc-r (Supplementary Fig. S1).

Mycelial growth and sclerotial development of OS and BS isolates of $\boldsymbol{B}$. cinerea. Six OS isolates (XN-1, S443, S417, S494, T415, and T417) and four BS isolates (B05.10, BC-27, HS-5, and WXt02-2) grew at radial growth rates of 14.8 to $17.6 \mathrm{~mm} /$ day on PDA at $20^{\circ} \mathrm{C}$ (Table 1). In all cases, the entire Petri dishes $(9 \mathrm{~cm}$ in diameter) were colonized within 3 days postincubation (dpi). Then, sclerotia were produced $6 \mathrm{dpi}$. For the OS isolates, the sclerotial color turned from white (primordia) to yellow at 9 to $11 \mathrm{dpi}$, then to orange at 15 to $28 \mathrm{dpi}$. For the BS isolates, however, the sclerotia color turned from white to gray at $9 \mathrm{dpi}$, then to black at 11 to $28 \mathrm{dpi}$ (Fig. 4). Isolate WXt02-2 appeared to be an intermediate between the OS and BS isolates regarding change of sclerotial color. It turned from white to yellow at 9 to $11 \mathrm{dpi}$, to light brown at $15 \mathrm{dpi}$, and, finally, became black at 28 dpi.

Deficiency in sclerotial melanogenesis in OS. Light-microscopic observation showed that the sclerotial structure of the OS isolate $\mathrm{XN}-1$ and the BS isolate B05.10 is quite similar, consisting of the cortex (outside), with compact parenchymatous cells, and the medulla (inside), with loose prosenchymatous cells (Fig. 5). The cells in the outer layer of the cortex were highly melanized for the black sclerotia produced by $\mathrm{B} 05.10$, whereas they were not melanized at all for the orange sclerotia produced by XN-1. TEM observation showed that the wall of the melanized cells in the black sclerotia contained electron-dense materials (EDM). However, the wall for the nonmelanized cells of XN-1 did not contain any visible EDM (Fig. 5). SEM observation showed that most cells in the outer layer of the cortex in the black sclerotia of B05.10 appeared plump and integrated. In contrast, most cells in the outer layer of the cortex in the orange sclerotia of XN-1 became shriveled and some cells even became disintegrated, with a sign of collapse.

Survival of sclerotia. Temperature and soil water content affected survival of the OS isolate $\mathrm{XN}-1$ and the BS isolate B05.10 (Fig. 6). At $10^{\circ} \mathrm{C}$, the sclerotia of both isolates survived very well in soil containing
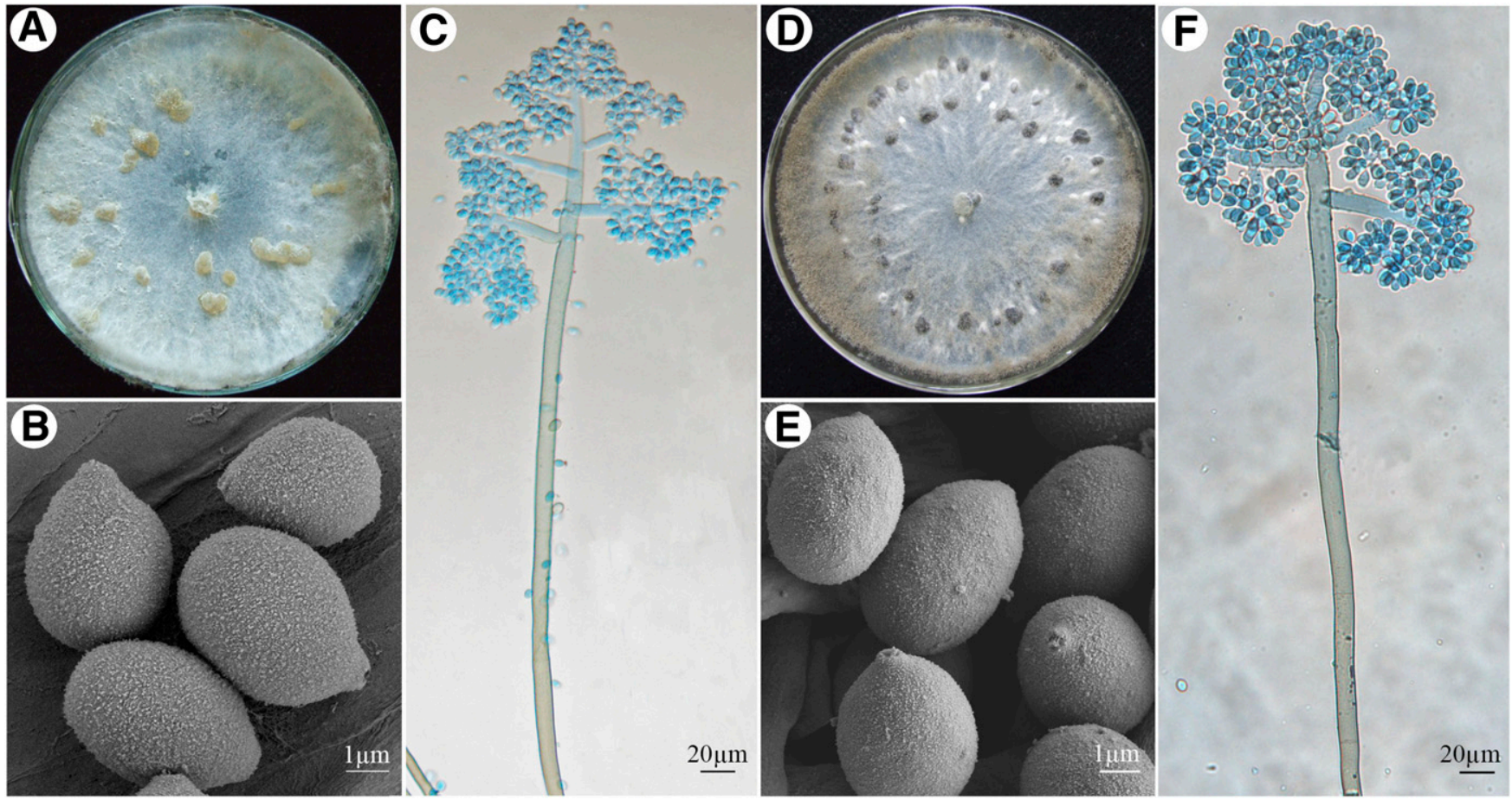

Fig. 3. Cultural and morphological characteristics of orange-colored sclerotial isolate $\mathrm{XN}-1$ and black-colored sclerotial B05.10 of Botrytis cinerea. A, A 20-day-old potato dextrose agar (PDA) culture of XN-1 $\left(20^{\circ} \mathrm{C}\right)$; B, conidiophore of XN-1 with clusters of conidia; C, scanning electron microscopy (SEM) micrograph showing four conidia of XN-1; D, 20-dayold PDA culture of B05.10 $\left(20^{\circ} \mathrm{C}\right)$; E, conidiophore of B05.10 with clusters of conidia; and F, SEM micrograph showing six conidia of B05.10. 
$6 \%$ water (vol/wt). At 360 dpi, the sclerotial survival rates were 93 and $100 \%$ for OS and BS, respectively. The AUSSC value for OS was similar to that for the BS in this treatment (Table 3). In 19 and 45\% soil water contents, however, survival of OS showed a sharp decline after $180 \mathrm{dpi}$, whereas the survival rate of BS remained as high as in 90 to $100 \%$ soil water contents. The AUSSC values for OS were reduced by 19.7 and $18.2 \%$ in 19 and $45 \%$ soil water contents, respectively, compared with the AUSSC values of BS (Table 3). At $20^{\circ} \mathrm{C}$, BS survived well in the soils containing 19 and $45 \%$ water but showed a sharp decline in survival as of 240 dpi in $6 \%$ soil water content. The trend differed from OS, with better survival rate in $6 \%$ soil water contents compared with 19 and $45 \%$ soil water contents (Fig. 6). Part of the reduction in survival rate for both $\mathrm{BS}$ and OS isolates in $6 \%$ soil water contents could be attributed to infection by a species of Penicillium since 210 and $270 \mathrm{dpi}$, respectively. The AUSSC values for OS were reduced by $18.5,71.7$, and $70.3 \%$ in 6,19 , and $45 \%$ soil water contents, respectively, compared with the AUSSC values of BS (Table 3). At $30^{\circ} \mathrm{C}$, both BS and OS survived very poorly regardless of soil water content (Fig. 6). Relatively, OS had lower survival rates or shorter survival duration than BS in soil. The AUSSC values for OS were reduced by $51.7,71.8$, and $38.7 \%$ in 6,19 , and $45 \%$ soil water contents, respectively, compared with the AUSSC values of BS (Table 3).

Sclerotial susceptibility to mycoparasitic infection. Both OS (XN-1) and BS (B05.10) treated with C. rosea and T. koningiopsis

Table 2. Morphological characteristics of sclerotia, conidiophores, and conidia formed by different isolates of Botrytis cinerea on potato dextrose agar at $20^{\circ} \mathrm{C}$ for 15 days $^{\mathrm{y}}$

\begin{tabular}{lccc}
\hline Isolate (GenBank accession number) ${ }^{\mathbf{z}}$ & Sclerotia (length $\times$ width, mm) & Conidiophores (length $\times$ width, $\boldsymbol{\mu m}$ ) & Conidia (length $\times$ width, $\boldsymbol{\mu m}$ ) \\
\hline XN-1 (KT266229) & $2.0-6.6 \times 1.6-4.4$ & $1,536-2,443 \times 10-14$ & $5.3-10.0 \times 3.5-8.8$ \\
S417 (KT266230) & $2.6-8.2 \times 2.0-5.2$ & $1,508-2,848 \times 10-15$ & $7.5-15.0 \times 5.0-9.1$ \\
T417 (KT266231) & $2.6-8.2 \times 2.0-7.0$ & $1,647-2,987 \times 9-15$ & $8.0-15.5 \times 6.5-11.0$ \\
BC-27 (EU563124) & $1.1-9.0 \times 0.9-2.8$ & $810-1,619 \times 13-17$ & $6.3-12.6 \times 6.0-9.4$ \\
HS-5 (KT266232) & $1.4-4.6 \times 1.0-4.0$ & $1,814-3,210 \times 11-15$ & $5.0-10.0 \times 3.1-9.7$ \\
B05.10 (not determined) & $2.4-5.4 \times 2.0-4.8$ & $1,954-3,210 \times 10-15$ & $6.3-12.7 \times 5.6-12.6$ \\
\hline
\end{tabular}

y In total, 30 sclerotia, 20 conidiophores, and 50 conidia were measured for each isolate.

${ }^{\mathrm{z}}$ GenBank accession numbers of the internal transcribed spacer sequences are presented in parentheses following the isolate names.

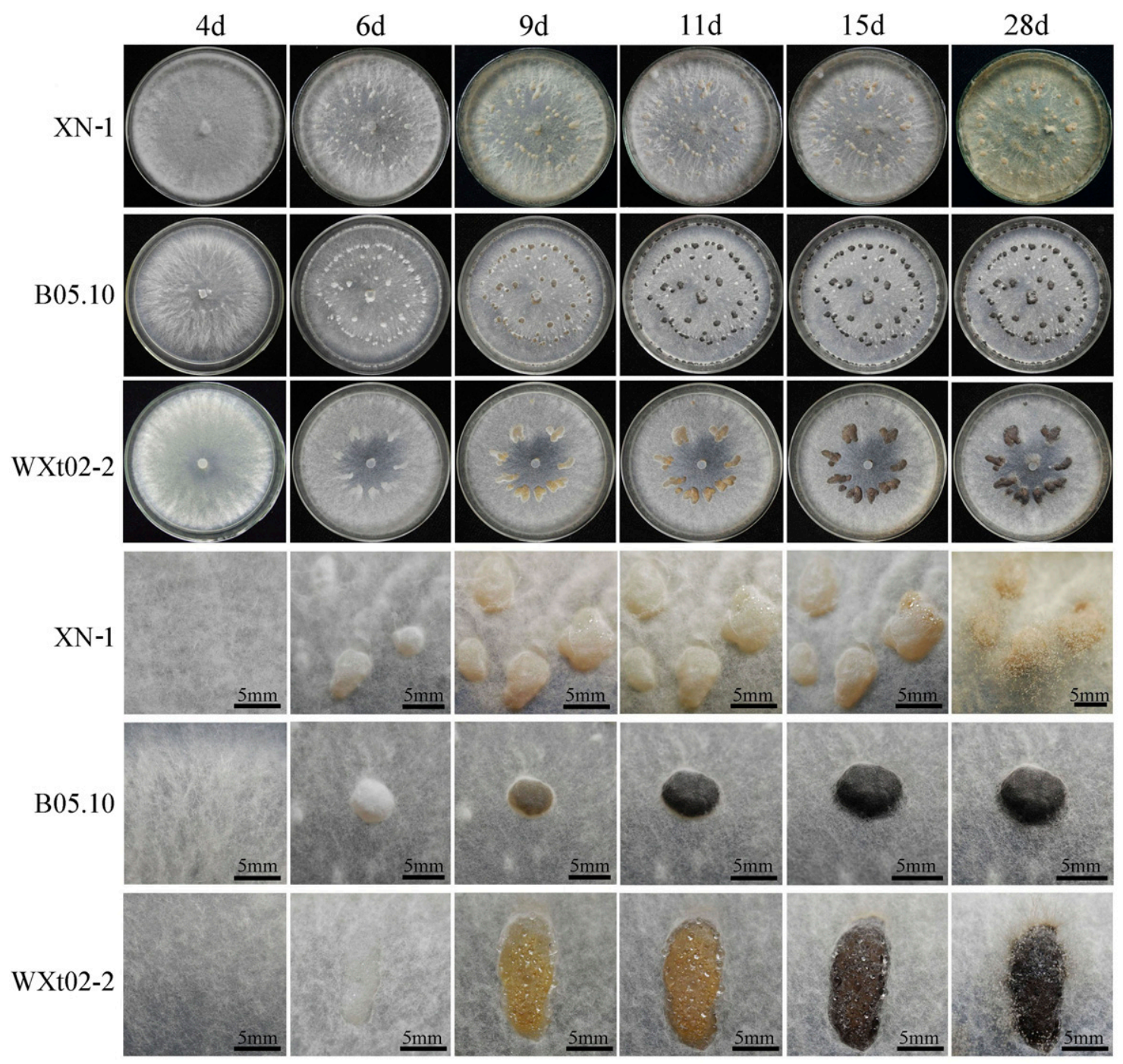

Fig. 4. Sclerotial development in isolates XN-1, B05.10, and WXt02-2 of Botrytis cinerea on potato dextrose agar incubated at $20^{\circ} \mathrm{C}$. Note the sporogenic germination of sclerotia produced by XN-1 and WXt02-2 in the 28-day-old cultures, indicating lack of sclerotial latency or dormancy. 
showed signs of mycoparasitism. The percentages of the mycoparasitism by each mycoparasite reached $100 \%$ on OS and BS (data not shown). The mycoparasitism was manifested by formation of pink (C. rosea) or green (T. koningiopsis) fungal colonies on the surface of the sclerotia. Further determination of sclerotial survival indicated that, although the sclerotia (BS or OS) treated with water alone remained intact and viable, the sclerotia (BS or OS) treated with C. rosea and $T$. koningiopsis were greatly reduced for survival (Fig. 7). OS survived by 22 and $20 \%$ in the treatments of $C$. rosea and T. koningiopsis, respectively. BS survived by 38 and $58 \%$, in
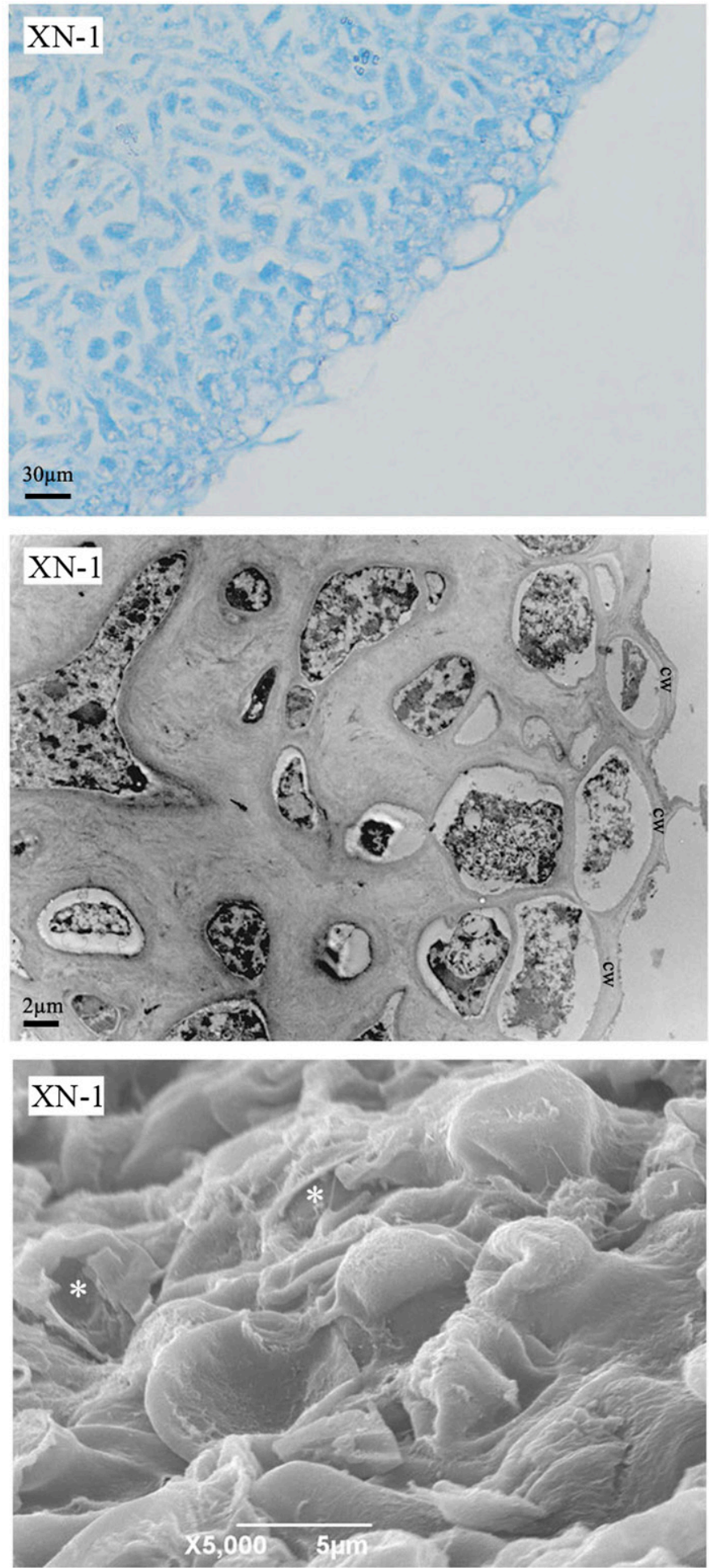

these two treatments, respectively. Statistical analysis also showed that the two sclerotial types differed significantly in percentages of VS following treatment with $C$. rosea $(P=0.0003)$ and $T$. koningiopsis $(P=0.0002)$.

Response to abiotic stresses. The OS (XN-1) and BS (B05.10) responded differently to $\mathrm{D}$-sorbitol ( $1 \mathrm{~mol} / \mathrm{liter}), \mathrm{NaCl}(50 \mathrm{~g} / \mathrm{liter})$, $\mathrm{H}_{2} \mathrm{O}_{2}(30 \% \mathrm{vol} / \mathrm{vol})$, and SDS (10\%, wt/vol) for survival. OS was more sensitive than $\mathrm{BS}$ to $\mathrm{H}_{2} \mathrm{O}_{2}$ at 1.5 to $2.5 \mathrm{~h}$ postincubation, to SDS at 4 and 5 hpi, to $\mathrm{NaCl}$ at 18 to $30 \mathrm{dpi}$, and to D-sorbitol at 30 dpi (Fig. 8).
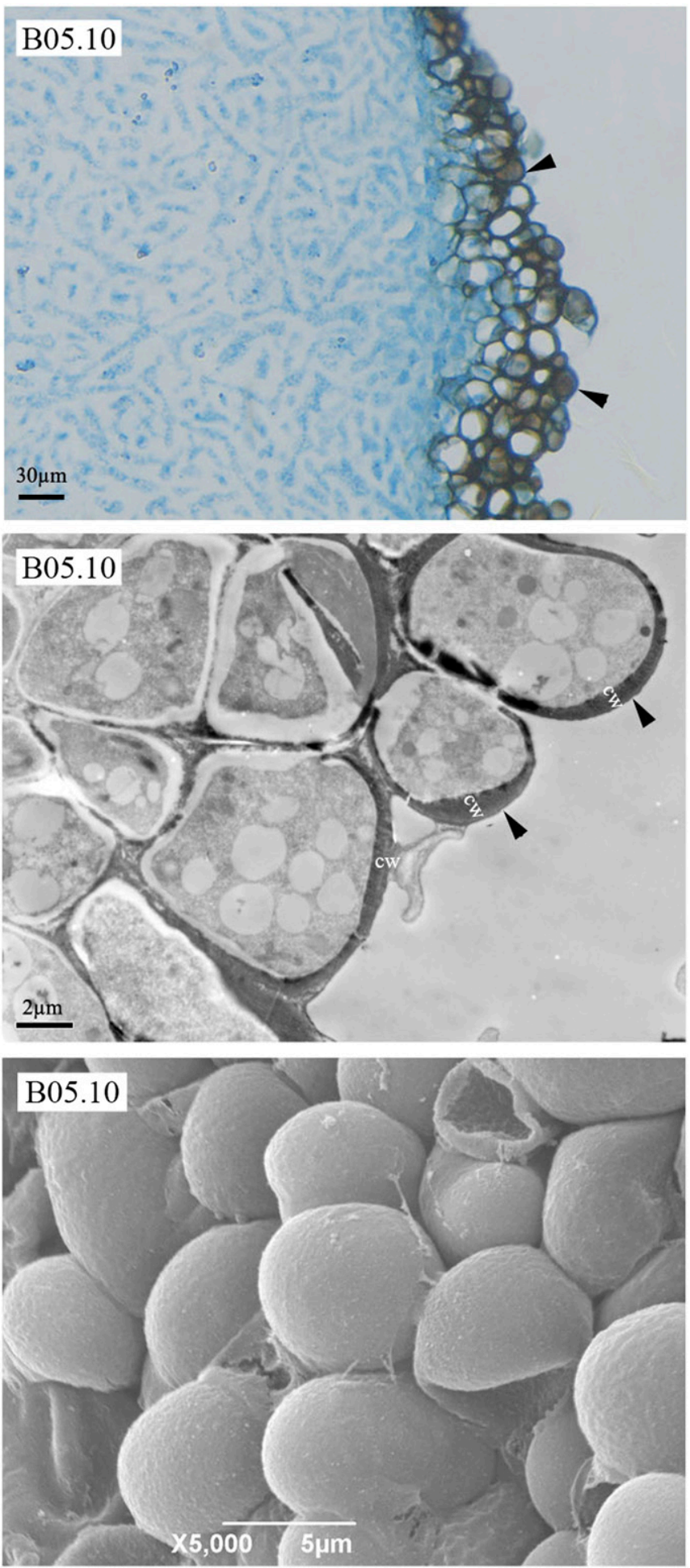

Fig. 5. Graphs of light microscopy (upper row), transmission electron microscopy (middle row), and scanning electron microscopy (bottom row) showing difference in melanin deposition and cell morphology of the sclerotial cortex of the orange-colored sclerotial isolate XN-1 and black-colored sclerotial isolate B05.10 of Botrytis cinerea. Black arrowheads indicate deposition of electron-dense materials (possibly melanin) in the cell wall. $\mathrm{CW}=$ cell wall and an asterisk $\left(^{*}\right)$ indicates ruptured cells. 


\section{Discussion}

Fungal species in the genus Botrytis, including B. cinerea, are known to produce BS on both agar media and, sometimes, infected plant tissues (Willetts and Bullock 1992; Williamson et al. 2007). In this study, we reported six OS-producing isolates of $B$. cinerea which never turned black. Five of these isolates were obtained from strawberry and tomato showing gray mold symptoms (Table 1; Fig. 2). To our knowledge, this is the first report of the natural existence of OS isolates of $B$. cinerea. Zhou (2017) also found that the trait of OS formation was a stable trait. Thus, the OS isolates can be potentially used to study sclerotial biology and epidemiology of $B$. cinerea.

Isolates $\mathrm{XN}-1$ (OS) and HS-5 (BS) of B. cinerea were isolated from the orange-colored apothecia of a soil fungus (Fig. 1) collected from a strawberry field in Xianning County, Hubei Province, China.
The apothecia were not produced by $\mathrm{XN}-1$ or HS-5, because the apothecia of $B$. cinerea are usually flesh and pale colored, rather than orange colored (Williamson et al. 2007). The orange-colored apothecia of our collection were formed on mycelia living in the soil (Fig. 1). Furthermore, we cloned the ITS-rDNA sequence (GenBank accession number MF784638) using the DNA template extracted from the fresh orange-colored apothecia. BLAST search indicated that the ITS-rDNA sequence is $99 \%$ identical to the uncultured soil fungus clone D123 (Supplementary Fig. S2). Therefore, the orange-colored apothecia collected in this study were produced by the uncultured soil fungus. The finding about existence of $B$. cinerea in the apothecia of an uncultured soil fungus is similar to the study by Liu et al. (2017), who reported that $B$. cinerea could be frequently isolated from the fruiting bodies (apothecia) of outdoor cultivated morel mushrooms (Morchella spp.). The
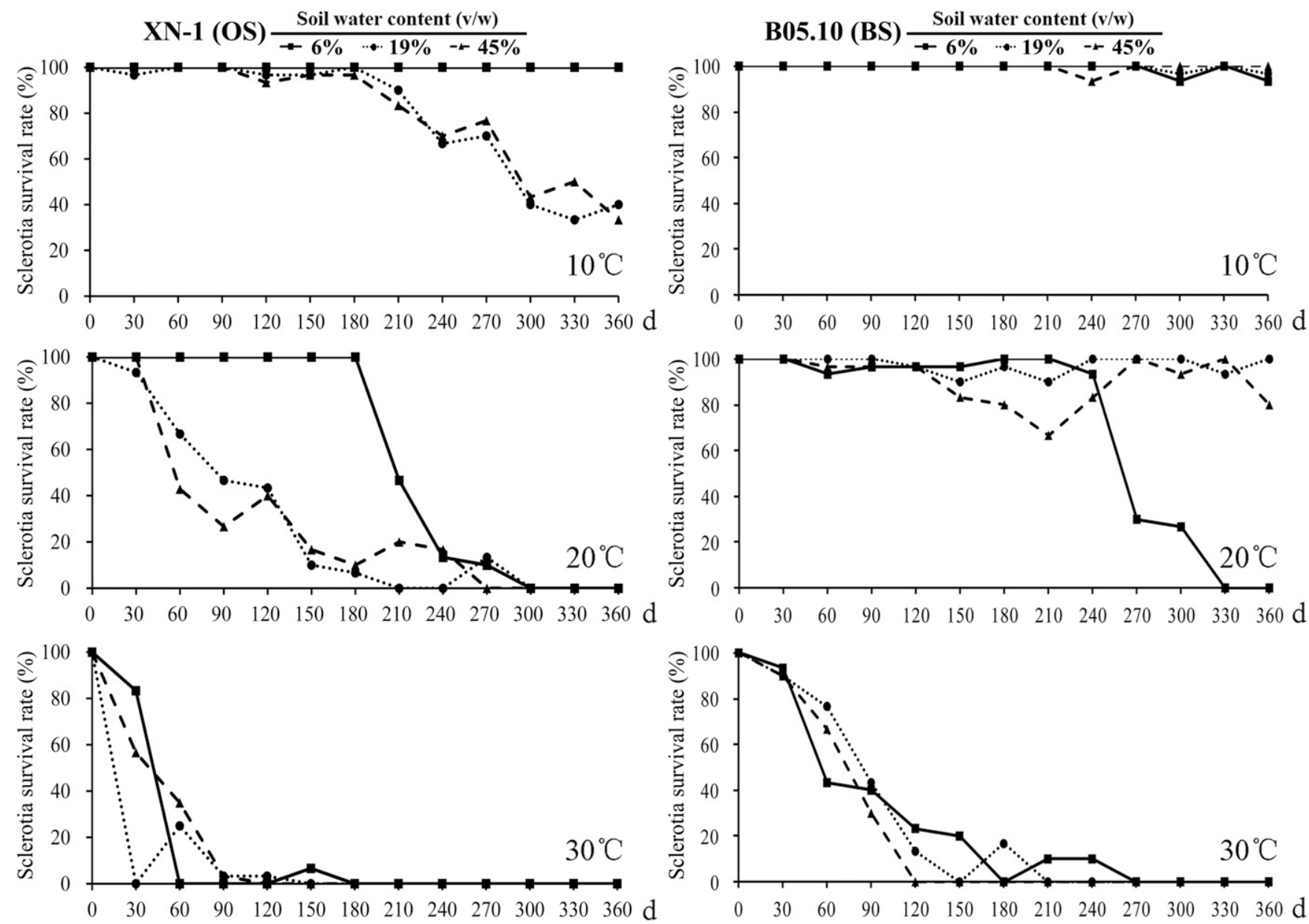

Fig. 6. Survival curves for the sclerotia of Botrytis cinerea isolates XN-1 (orange-colored sclerotia, OS) and B05.10 (black-colored sclerotia, BS) at 10,20 , and $30^{\circ} \mathrm{C}$ in soil with different water contents.

Table 3. Comparison of the area under the sclerotial survival curve (AUSSC) between the isolates B05.10 (black-colored sclerotia) and XN-1 (orange-colored sclerotia) of Botrytis cinerea

\begin{tabular}{lccc}
\hline & \multicolumn{2}{c}{ AUSSC } & XN-1 \\
\cline { 2 - 3 } Treatment & $\mathbf{B 0 5 . 1 0}$ & 36,000 & Reduction in XN-1 vs. B05.10 $(\%))^{\mathbf{z}}$ \\
\hline $10^{\circ} \mathrm{C}$ and $6 \%$ soil water content & 35,700 & 28,800 & -0.8 \\
$10^{\circ} \mathrm{C}$ and $19 \%$ soil water content & 35,850 & 29,300 & 19.7 \\
$10^{\circ} \mathrm{C}$ and $45 \%$ soil water content & 35,800 & 21,600 & 18.2 \\
$20^{\circ} \mathrm{C}$ and $6 \%$ soil water content & 26,500 & 9,900 & 18.5 \\
$20^{\circ} \mathrm{C}$ and $19 \%$ soil water content & 34,997 & 9,686 & 71.7 \\
$20^{\circ} \mathrm{C}$ and $45 \%$ soil water content & 32,597 & 4,200 & 70.3 \\
$30^{\circ} \mathrm{C}$ and $6 \%$ soil water content & 8,700 & 2,450 & 51.7 \\
$30^{\circ} \mathrm{C}$ and $19 \%$ soil water content & 8,700 & 4,350 & 71.8 \\
$30^{\circ} \mathrm{C}$ and $45 \%$ soil water content & 7,100 & 38.7 \\
\hline
\end{tabular}

${ }^{\mathrm{z}}$ Reduction of AUSSC in XN-1 compared with that in B05.10. Reduction $(\%)=\left(\mathrm{AUSSC}_{\mathrm{B} 05.10}-\mathrm{AUSSC}_{\mathrm{XN}-1}\right) / \mathrm{AUSSC}_{\mathrm{B} 05.10} \times 100 \%$. 
orange-colored apothecia in our collection and the fruiting bodies of morel mushrooms (Liu et al. 2017) appeared healthy, without any signs of gray mold symptoms, indicating that $B$. cinerea may not be the pathogen of these fungi. It may just dwell on the surface or inside the fungal apothecia.

The present study revealed that the OS isolates of $B$. cinerea accounted for only $0.25 \%$ of a total 2,031 isolates. Moreover, all 922 isolates of $B$. cinerea from the same location in Xianning County, where the first OS isolate $(\mathrm{XN}-1)$ was isolated, belonged to the BS type. These results suggest that the OS $B$. cinerea is the minority in populations. Low frequency of the OS isolates of $B$. cinerea implies

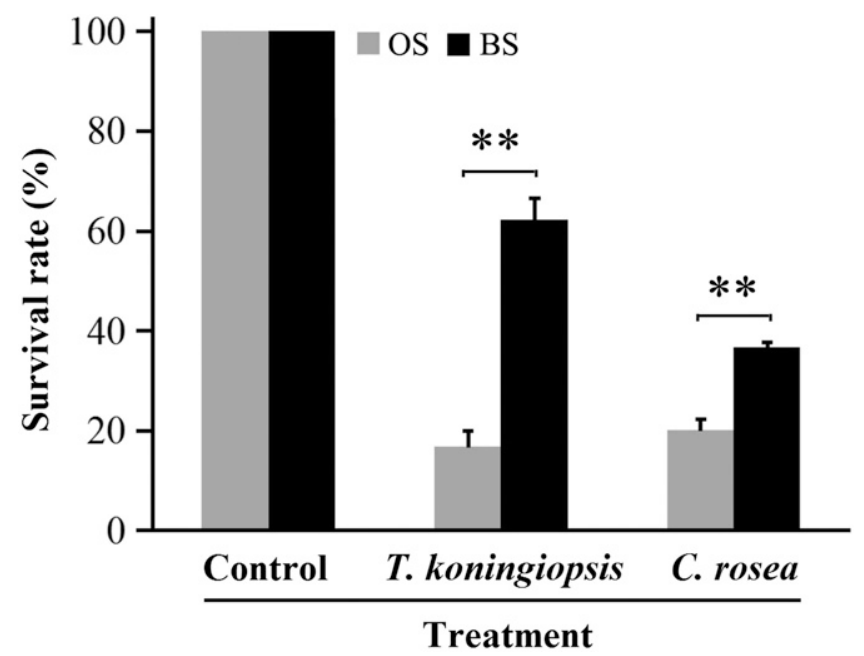

Fig. 7. Percentages of the viable sclerotia of isolates $\mathrm{XN}-1$ (orange-colored sclerotia, OS) and B05.10 (black-colored sclerotia, BS) of Botrytis cinerea in the treatments of water alone (Control), Clonostachys rosea, and Trichoderma koningiopsis $\left(28^{\circ} \mathrm{C}, 20\right.$ days); ${ }^{* *}$ indicates $P<0.01$ (Student's $t$ test) between isolates $\mathrm{XN}-1$ and $\mathrm{B} 05.10$. that the sclerotial melanin-deficient isolates might be less fitted to the natural environment than the BS counterparts of $B$. cinerea.

As defined previously, the term "fitness" means the ability of a fungus to grow, reproduce, and survive in the environment (Pringle and Taylor 2002). Many parameters have been used in previous studies to estimate ecological fitness of fungicide-resistant isolates of B. cinerea (Kim and Xiao 2011; Lalève et al. 2014; Raposo et al. 1996; Veloukas et al. 2014). The parameters include (i) mycelial growth rate; (ii) conidial production, survival, and germination; (iii) sclerotial production, survival, latency, and germination; (iv) response to reactive oxygen species and osmotic pressure; (v) pathogenicity (or aggressiveness) and competitive ability; and (v) sexual reproduction. In this study, many fitness-related parameters were measured and compared between the $\mathrm{OS}$ isolate $\mathrm{XN}-1$ and the $\mathrm{BS}$ isolate $\mathrm{B} 05.10$. Both grew vigorously at $20^{\circ} \mathrm{C}$ on agar media with formation of conidia and sclerotia (Fig. 4). $\mathrm{XN}-1$ was similar to B05.10 in many biological aspects, including mycelial growth rates on PDA at $20^{\circ} \mathrm{C}$, conidial germination rate on WA at $20^{\circ} \mathrm{C}$ (Table 1), survival as mycelia and conidia, and response to abiotic stresses (Zhou 2017). Moreover, the OS isolates (XN-1, S417, and T417) are similar to BS isolates (B05.10, BC-27, and HS-5) in infection of leaves of oilseed rape (Brassica napus) and tobacco (Nicotiana benthamiana) (Zhou 2017). All these results suggest that the OS isolate $\mathrm{XN}-1$ as mycelia and conidia is similar to the BS isolate B05.10 in ecological fitness.

In contrast, we found that $\mathrm{XN}-1$ differed greatly from $\mathrm{B} 05.10$ in sclerotial survival in soil at 10,20 , and $30^{\circ} \mathrm{C}$ (Fig. 6). In all the treatments, except in soil with low soil water content at $10^{\circ} \mathrm{C}$, the OS of $\mathrm{XN}-1$ had lower survival rates or shorter survival duration than the BS of B05.10. Therefore, the fitness level of the sclerotia of $\mathrm{XN}-1$ is lower than that of the sclerotia of B05.10. Two mechanisms might be responsible for poor survival of the sclerotia of $\mathrm{XN}-1$, according to this study. First, the sclerotia of XN-1 lack dormancy and usually conduct sporogenic germination without latency under suitable conditions (e.g., $20^{\circ} \mathrm{C}$ and humid). Second, the $\mathrm{OS}$ of $\mathrm{XN}-1$ are more susceptible than the BS of B05.10 to infection by mycoparasites such as $C$. rosea and $T$. koningiopsis, possibly due to abnormality (collapse
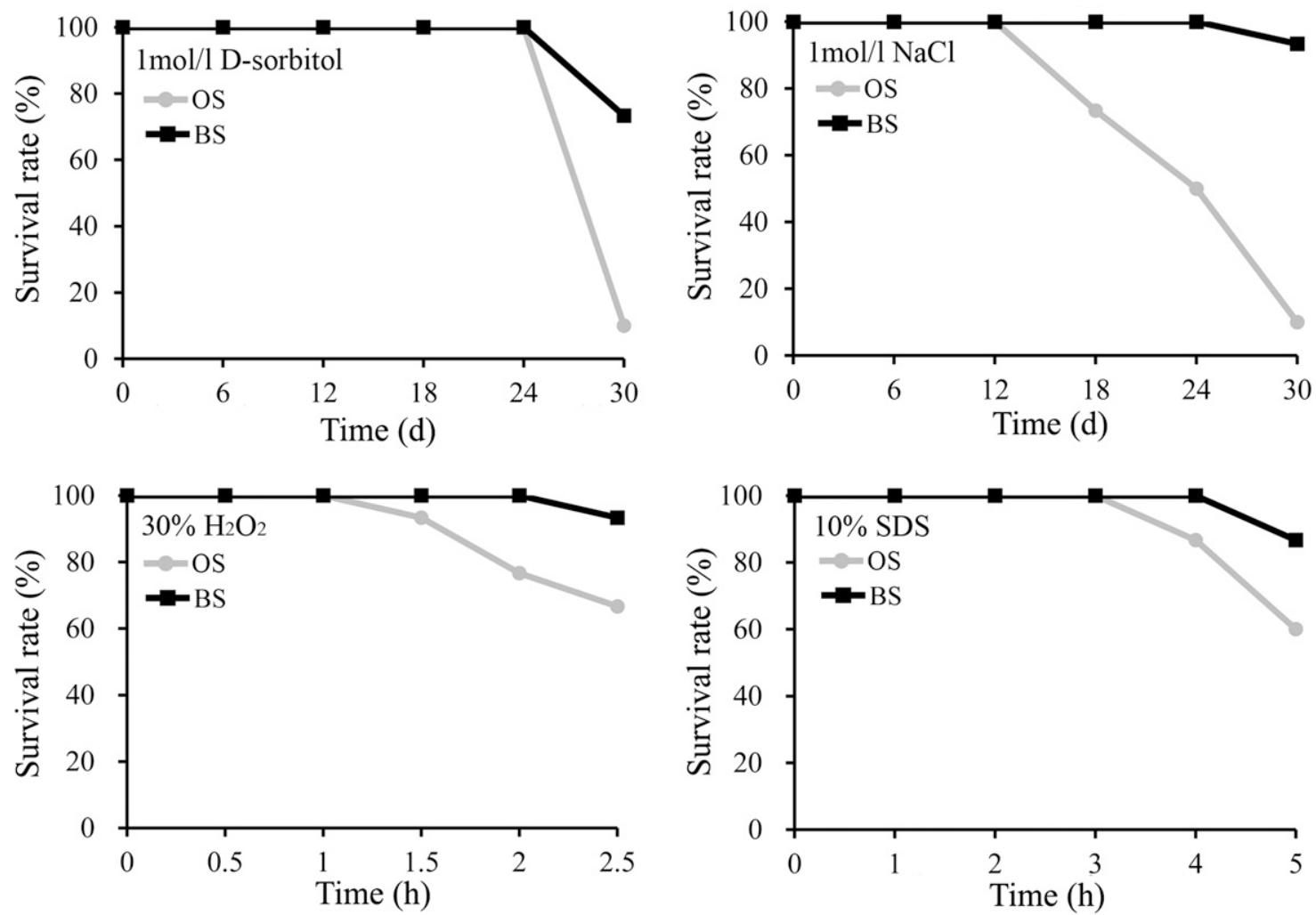

Fig. 8. Percentages of the viable sclerotia of isolates $\mathrm{XN}-1$ (orange-colored sclerotia, $\mathrm{OS}$ ) and $\mathrm{B} 05.10$ (black-colored sclerotia, $\mathrm{BS}$ ) in response to osmotic pressure (D-sorbitol and $\mathrm{NaCl})$, hydrogen peroxide $\left(\mathrm{H}_{2} \mathrm{O}_{2}\right)$, and sodium dodecyl sulfate (SDS). 
or disintegration) of the cortex cells in the sclerotia. Taking all of the results about ecological fitness into account, we can draw a preliminary conclusion that reduced sclerotial fitness of the OS isolate $\mathrm{XN}-1$ is probably the main reason for its rare occurrence in nature. From this conclusion, an inference can be made that sclerotia may play an important role in natural epidemics of Botrytis cinerea.

The importance of sclerotia of $B$. cinerea is often questioned (Raposo et al. 1996; Yunis and Elad 1989), because they are not frequently observed in susceptible corps (Williamson et al. 2007). This superficial phenomenon may mask or underestimate the importance of sclerotia in natural epidemics of $B$. cinerea. It is well known that $B$. cinerea usually occurs in a polycyclic pattern, mostly driven by asexual reproduction (conidia) on sclerotia or vegetative mycelia in various plant debris. It is possible that a small number of VS/mycelia in the environment can be enough to initiate buildup of the populations of $B$. cinerea under suitable environmental conditions within a short period.

This study found that isolates $\mathrm{XN}-1$ and B05.10 differed greatly in sclerotial melanogenesis, which is present in B05.10, thus forming $\mathrm{BS}$, but is absent in XN-1, thus forming OS. Schumacher (2016) reported that at least five genes, including Bcsmrl (for a transcription factor), Bcpks 12 (for a polyketide synthase), Bcbrn1/2 (for two reductases), and Bcscd 1 (for a dehydratase), are required for sclerotial melanogenesis of $B$. cinerea. Mutation or suppression of expression of these genes may cause deficiency in sclerotial melanogenesis in $B$. cinerea. The molecular defects that cause formation of the OS by the OS isolates of $B$. cinerea are under investigation.

\section{Acknowledgments}

This study was financially supported by the National Natural Science Foundation of China (grant number 31571955) and China's Special Fund for AgroScientific Research in the Public Interest (grant number 201303025). We thank Z. Ma (Zhejiang University, Hangzhou, China) for providing isolate B05.10 of B. cinerea and B.-C. Xu (Wuhan Institute of Virology, CAS, Wuhan, China) for technical support in SEM and TEM observation.

\section{Literature Cited}

Dean, R., van Kan, J. A. L., Pretorius, Z. A., Hammond-Kosack, K. E., di Pietro, A., Spanu, P. D., Rudd, J. J., Dickman, M., Kahmann, R., Ellis, J., and Foster, G. D. 2012. The top 10 fungal pathogens in molecular plant pathology. Mol. Plant Pathol. 13:414-430.

Elad, Y., Pertot, I., Cotes Prado, A. M., and Stewart, A. 2016. Plant hosts of Botrytis spp. Pages 413-486 in: Botrytis-The Fungus, the Pathogen and its Management in Agricultural Systems. S. Fillinger and Y. Elad, eds. Springer International Publishing AG, Cham, Switzerland.

Fan, X., Zhang, J., Yang, L., Wu, M. D., Chen, W. D., and Li, G. Q. 2015. Development of PCR-based assays of detecting and differentiating three species of Botrytis infecting broad bean. Plant Dis. 99:691-698.

Howard, R. J., and Valent, B. 1996. Breaking and entering: Host penetration by the fungal rice blast pathogen Magnaporthe grisea. Annu. Rev. Microbiol. 50: 491-512.
Hsiang, T., and Chastagner, G. A. 1992. Production and viability of sclerotia from fungicide-resistant and fungicide-sensitive isolates of Botrytis cinerea, B. elliptica and B. tulipae. Plant Pathol. 41:600-605.

Kim, Y. K., and Xiao, C. L. 2011. Stability and fitness of pyraclostrobin- and boscalid-resistant phenotypes in field isolates of Botrytis cinerea from apple. Phytopathology 101:1385-1391.

Kubo, Y., Suzuki, K., Furusawa, I., and Yamamoto, M. 1982. Effect of tricyclazole on appressorial pigmentation and penetration from appressoria of Colletotrichum lagenarium. Phytopathology 72:1198-1200.

Lalève, A., Fillinger, S., and Walker, A. S. 2014. Fitness measurement reveals contrasting costs in homologous recombinant mutants of Botrytis cinerea resistant to succinate dehydrogenase inhibitors. Fungal Genet. Biol. 67:24-36.

Liu, W., Zhang, Y., and He, P. X. 2017. Pages 155-156 in: Morel Biology and Cultivation. Jilin Science and Technology Press, Chang Chun, China.

Polach, F. J., and Abawi, G. S. 1975. The occurrence and biology of Botryotinia fuckeliana on beans in New York. Phytopathology 65:657-660.

Pringle, A., and Taylor, J. W. 2002. The fitness of filamentous fungi. Trends Microbiol. 10:474-481.

Raposo, R., Delcan, J., Gomez, V., and Melgarejo, P. 1996. Distribution and fitness of isolates of Botrytis cinerea with multiple fungicide resistance in Spanish greenhouses. Plant Pathol. 45:497-505.

Salinas, J., Glandorf, D. C. M., Picavet, F. D., and Verhoeff, K. 1989. Effects of temperature, relative humidity and age of conidia on the incidence of spotting on gerbera flowers caused by Botrytis cinerea. Eur. J. Plant Pathol. 95:51-64.

Schumacher, J. 2016. DHN melanin biosynthesis in the plant pathogenic fungus Botrytis cinerea is based on two developmentally regulated key enzyme (PKS)-encoding genes. Mol. Microbiol. 99:729-748.

Veloukas, T., Kalogeropoulou, P., Markoglou, A. N., and Karaoglanidis, G. S. 2014. Fitness and competitive ability of Botrytis cinerea field isolates with dual resistance to SDHI and QoI fungicides, associated with several sdhB and the cytb G143A mutations. Phytopathology 104:347-356.

Walter, M., Boyd-Wilson, K. S. H., Perry, J. H., Elmer, P. A. G., and Framptonm, C. M. 1999. Survival of Botrytis cinerea conidia on kiwifruit. Plant Pathol. 48:823-829.

Willetts, H. J., and Bullock, S. 1992. Developmental biology of sclerotia. Mycol. Res. 96:801-816.

Williamson, B., Tudzynski, B., Tudzynski, P., and van Kan, J. A. L. 2007. Botrytis cinerea: The cause of grey mould disease. Mol. Plant Pathol. 8:561-580.

You, J. Q., Zhang, J., Wu, M. D., Yang, L., Chen, W. D., and Li, G. Q. 2016. Multiple criteria-based screening of Trichoderma isolates for biological control of Botrytis cinerea on tomato. Biol. Control 101:31-38.

Yunis, H., and Elad, Y. 1989. Survival of dicarboximide-resistant strains of Botrytis cinerea in plant debris during summer in Israel. Phytoparasitica 17:13-21.

Zeun, R., and Buchenauer, H. 1985. Effect of tricyclazole on production and melanin contents of sclerotia of Botrytis cinerea. J. Phytopathol. 112:259-267.

Zhang, J., Wu, M. D., Li, G. Q., Yang, L., Yu, L., Jiang, D. H., Huang, H. C., and Zhuang, W. Y. 2010. Botrytis fabiopsis, a new species causing chocolate spot of broad bean in central China. Mycologia 102:1114-1126.

Zhang, Q. H., Zhang, J., Yang, L., Zhang, L., Jiang, D. H., Chen, W. D., and Li, G. Q. 2014. Diversity and biocontrol potential of endophytic fungi in Brassica napus. Biol. Control 72:98-108.

Zhou, Y. J. 2017. Biological and molecular characterization of the rare orangecolored sclerotial isolates of Botrytis cinerea. Ph.D. thesis, Huazhong Agricultural University, Wuhan, China.

Zhou, Y. J., Zhang, J., Wang, X. D., Yang, L., Jiang, D. H., Li, G. Q., Hsiang, T. and Zhuang, W. Y. 2014. Morphological and phylogenetic identification of Botrytis sinoviticola, a novel cryptic species causing gray mold disease of table grapes (Vitis vinifera) in China. Mycologia 106:43-56. 